\title{
Development of Power Weeder for Line Sown Paddy Crop
}

\author{
Ragesh K.T., S.V. Jogdand, V.M. Victor, K.K.S. Mahilang and P. Pradan
}

Department of Farm Machinery and Power Engineering, SVCAET\&RS, IGKV, Raipur, India

*Corresponding author: rageshkt01@gmail.com (ORCID ID: 0000-0002-5473-0506)

Paper No. 790

Received: 17-04-2019

Revised: 15-07-2019

Accepted: 22-08-2019

\begin{abstract}
Weed is the main menace in paddy cultivation and its eradication from the paddy field is difficult and time consuming process. Traditional method of hand weeding is time consuming and labour intensive. Another method of weed control, through chemical method by weedicides is simple and fast method but is restricted due to its adverse effects on both environment as well as human beings. To overcome this, mechanical method by self - propelled weeders can replace this constraint. A power weeder was designed and developed for upland paddy and is tested for its field performance. The machine depicted satisfactory performance for weeding at both 20 and $45 \mathrm{DAS}$ and fuel efficient $\left(0.63\right.$ to $\left.0.7 \mathrm{lh}^{-1}\right)$ with weeding efficiency as $74.20 \%$ and $85.90 \%$ for weeding at 20 and 45 DAS respectively. The machine showed satisfactory result by less plant damages of 3.75 and $8.26 \%$ at 20 and 45 DAS respectively. The field efficiency of weeder at 45 DAS was $8.5 \%$ more than that of 20DAS.

Highlights

(0 Power weeder intends in the replacement of human labour

( Appropriate for weed management for small and medium farmers for commercial cultivation

( L Low plant damage and high weeding efficiency promotes affordability and adjustability of this machine for upland paddy crops
\end{abstract}

Keywords: Field efficiency, paddy, power weeder, weeding efficiency, weeds

Rice is the major crop produced and consumed over half of the world population. Being a tropical crop requires high rainfall, humidity and requisite temperature which are also a congenital factor for the growth and development of weed flora. Weed accounts in reduction of the crop yield which ranges from 40 to $65 \%$ (Sharma et al. 1977) and accounts one third of cost of cultivation (Rangaswamy et al. 1993) with an average time consumption of 300 to 1200 human-hours per hectare for weeding (Datta et al., 1974). The average cost of weeding is ₹ $945 \mathrm{ha}^{-1}$, out of ₹ $3000 \mathrm{ha}^{-1}$ for the total cost of cultivation for agricultural crops (Tajuddin et al. 1991).

The eradication of weed by hand weeding is a labour intensive, expensive and time consuming process. To overcome this, self- propelled weeders play a vital role in the weed management in the view point of lower time consumption, easy operation and quality of weeding. As a measure of weed control, Victor et al. (2003), designed and developed a $0.5 \mathrm{hp}$ engine run rotary weeder with four " $L$ " shaped cutting blades system for wetland paddy. The machine showed satisfactorily result by giving field capacity ranges from 0.04 to 0.06 ha $\mathrm{h}^{-1}$, field efficiency of $71 \%$ and weeding efficiency of $90.5 \%$. Tajuddin, (2006) designed, developed and tested an engine operated weeder and reported effective field capacity as 0.10 ha $\mathrm{h}^{-1}$ field efficiency as $85.71 \%$, weeding efficiency as $85.85 \%$, cost of operation as $₹ 580 \mathrm{ha}^{-1}$. The machine showed the fuel efficiency as 0.60 to 0.75 litres of kerosene per hour. Mahilang et al. (2013), designed, developed and fabricated a rotory paddy power weeder with $1.4 \mathrm{hp}$ petrol start kerosene run engine as prime mover. The power was transmitted by means of belt and pulley system from engine to traction wheel 
and to the cutting units. For cutting, six standard "L" shaped blades were provided on the hub which in turn was fitted on the rotary shaft. The weeding efficiency $(91 \%)$, quality of work done $(14 \%)$, field efficiency $(60 \%)$ and operational cost was found to be ₹ $808.42 \mathrm{ha}^{-1}$.

The study was conducted at Swami Vivekananda College of Agricultural Engineering Technology \& Research Station (SVCAET\&RS,), IGKV, Raipur (CG), India by fabricating and testing of paddy power weeder for summer season upland paddy crop in the year 2014-15. The machine was fabricated at the research workshop and tested at research field of the faculty.

\section{MATERIALS AND METHODS}

The developed paddy power weeder consist of main frame, power unit, reduction unit, power transmission system, rotary cutting unit, ground wheel gauge wheel, handle and mud flap. The design parameters of the developed paddy power weeder are as follows.

\section{Main frame}

The main frame is made of MS $35 \times 35 \times 5 \mathrm{~mm}$ angle iron on which the engine and gear box are fastened.

\section{Power unit and reduction unit}

A 1.4hp petrol start kerosene run engine (3000 rpm) is used as power unit. The engine rpm is reduced to $300 \mathrm{rpm}$ with help of a reduction gear box at a ratio of 10:1.

\section{Power transmission}

The power transmissions from gear box to ground wheel and rotary cutting unit are done by means of different combination of chain and sprocket system. The diameter of sprockets, number of teeth and rpm of sprockets are determined as follows (Khurmi, 2005):

$$
\begin{aligned}
& N_{1}=N_{2} \times \frac{D_{2}}{D_{1}} \\
& N^{\prime}=N^{\prime \prime} \times \frac{T_{1}}{T_{2}}
\end{aligned}
$$

Where, $N_{1}$ and $N^{\prime}=$ rpm of the driven sprocket, $N_{2}$ and $N^{\prime \prime}=$ rpm of the drive sprocket, $D_{1}=$ diameter of the driven sprocket, $D_{2}=$ diameter of the drive sprocket, $T_{1}=$ number of teeth in drive sprocket and $T_{2}=$ number of teeth in driven sprocket. Thus, the final reduction of rpm from engine (3000 rpm) reduced to $300 \mathrm{rpm}$ at gear box, $25 \mathrm{rpm}$ at ground wheel and $600 \mathrm{rpm}$ at the rotary cutter shaft (rotary blades). The schematic diagram of the power transmission system of paddy power weeder is shown in Fig. 1.

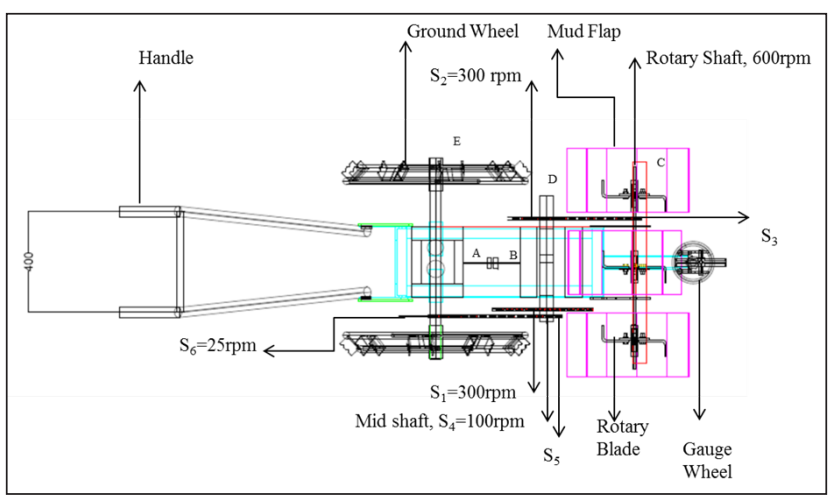

Fig. 1: Schematic diagram of the power transmission system

\section{Rotary cutting unit}

Weeding are done by front mounted, three units of rotary cutting blades. Each unit consist of four " $L$ " shaped blades with a cutting length of $5 \mathrm{~cm}$, fixed orthogonally on each rotary flange which is attached to the rotary shaft.

\section{Ground wheel axle shaft}

The shaft subjects both bending moments as well as twisting moment, then the shaft is to be designed by considering both moments simultaneously. According to maximum shear stress theory or Guest's theory the diameter of shaft is designed as follows by considering the permissible shear stress $\left(F_{s}\right)$, bending moment $(M)$ and torque $(T)$ on the axle shaft.

$$
d=3{\sqrt{\frac{16\left(M^{2}+T^{2}\right)}{\pi \times f_{s}}}}^{0.5}
$$

Hence, $25 \mathrm{~mm}$ diameter MS rod of $700 \mathrm{~mm}$ length is selected as ground wheel axle shaft. The ground wheel were made of two rings as inner ring (530 $\mathrm{mm}$ ) and outer ring $(450 \mathrm{~mm})$ of different diameter for preventing the jerking in undulated fields and for smooth field operation on which lugs are 
welded. Three mild steel rods are welded to outer and inner rings respectively as spokes from the central hub of ground wheel.

\section{Gauge wheel}

A gauge wheel of diameter $152.4 \mathrm{~mm}$ is attached to the front of the frame for depth adjustments of the rotary blades. A $10.5 \mathrm{~mm}$ diameter bush is provided on which 4 numbers of spokes were fixed for better strength of gauge wheel. The gauge wheel is attached to the frame with the help of two standards of $16 \mathrm{~mm}$ diameter and length of $360 \mathrm{~mm}$. For adjustments such as raising and lowering the gauge wheel, a threaded bolt of $18 \mathrm{~mm}$ diameter and $355 \mathrm{~mm}$ length are provided so as to alter the depth of cutting and weeding by the rotary blades. The different component of developed paddy power weeder is delineated in Fig. 2.

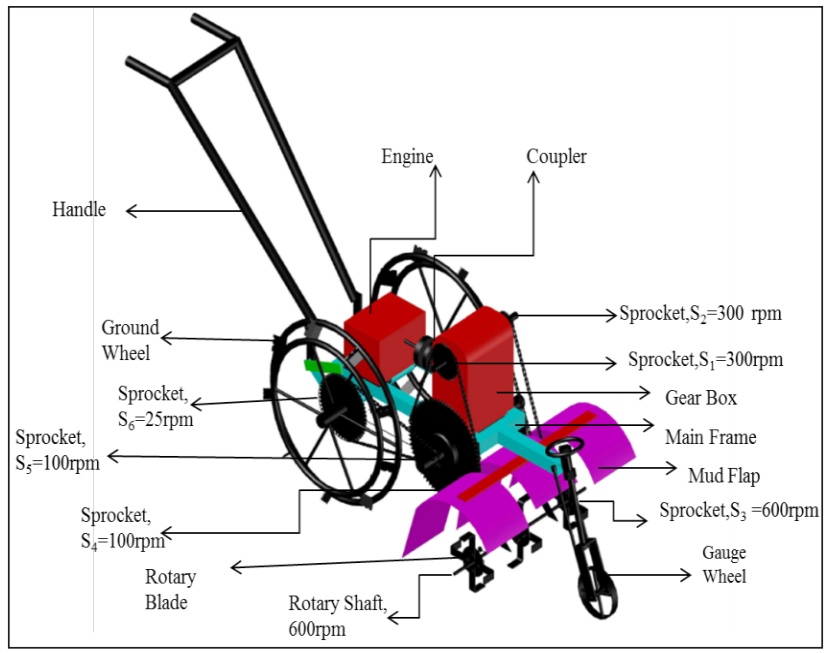

Fig. 2: Different components of designed and developed paddy power weeder

\section{Handle}

Handles are made of $25 \mathrm{~mm}$ MS conduit pipe with plastic grip fitted at the ends. The overall length of handle is $1160 \mathrm{~mm}$ and with a height of $900 \mathrm{~mm}$ from ground level. The length of handle cross bar is $400 \mathrm{~mm}$ and length of handle grip is $180 \mathrm{~mm}$. With help of handle, machine can be steered. A throttle lever is provided on right side of the handle to control the engine speed (Varshney et al. 2004).

\section{Mud flap}

To avoid throwing of mud and stones towards operator and as a safety measure, a mud flap is provided covering the upper and rear side of the blades of the rotary cutting units. It is made up of MS sheet, 18 gauge of length $460 \mathrm{~mm}$ and width 190 $\mathrm{mm}$. Table 1 shows the specification of the designed and developed power weeder as shown in Fig. 3.

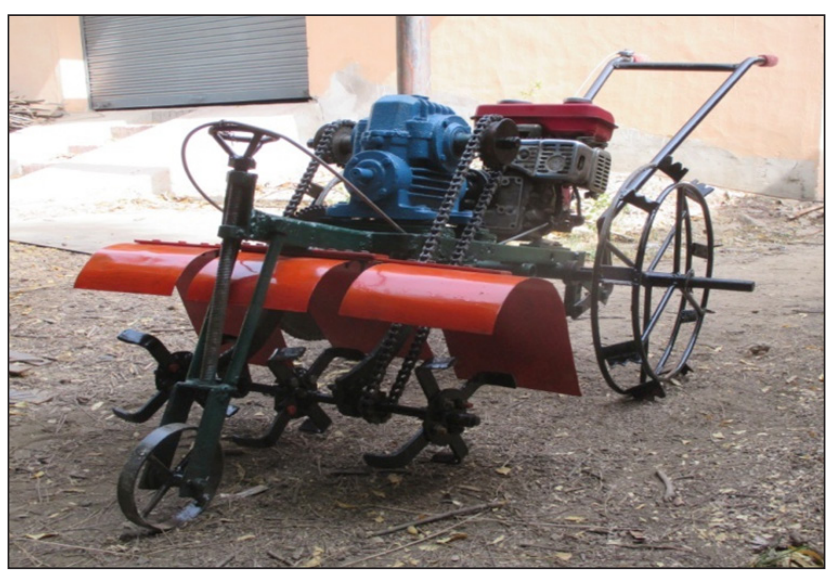

Fig. 3: Designed and modified paddy power weeder

Table 1: Specifications of developed power weeder

\begin{tabular}{|c|c|c|}
\hline $\begin{array}{l}\text { Sl. } \\
\text { No. }\end{array}$ & Particulars & Specifications \\
\hline 1 & Name and type & $\begin{array}{l}\text { Paddy power weeder, } 3 \\
\text { row walk behind type }\end{array}$ \\
\hline 2 & Make and model & Prototype \\
\hline 3 & Power source & $\begin{array}{l}1.4 \mathrm{hp} \text {, single cylinder, } \\
\text { Petrol start kerosene run, } \\
\text { Air cooled engine }\end{array}$ \\
\hline 4 & Over all dimensions & 1900x700x900 mm \\
\hline 5 & Weight & $98 \mathrm{~kg}$ \\
\hline 6 & $\begin{array}{l}\text { Cutting unit and Blade } \\
\text { type }\end{array}$ & $\begin{array}{l}\text { Rotary type, "L" shaped } \\
\text { blade }\end{array}$ \\
\hline 7 & Number of blades & $\begin{array}{l}12 \text { Nos. ( } 3 \text { rows } 4 \text { blades } \\
\text { per row) }\end{array}$ \\
\hline 8 & Blade cutting length & $50 \mathrm{~mm}$ \\
\hline 9 & Wheels & $\begin{array}{l}\text { Two ground wheel and one } \\
\text { gauge wheel at front end }\end{array}$ \\
\hline 10 & Cost of machine & ₹ 30,875/- \\
\hline
\end{tabular}

\section{Machine performance and evaluation}

\section{Weeding efficiency}

The weeding efficiency of the power weeder was determined as the ratio between the numbers of weeds removed by power weeder to the number of weeds present in a unit area and is expressed as a percentage (Tajuddin 2006). 


$$
n_{w}=\frac{w_{1}-w_{2}}{w_{1}}
$$

Where, $w_{1}$ and $w_{2}$ are the number of weeds present per unit area at before and after the weeding operation.

\section{Plant damaged}

It is the ratio of the number of plants damaged after operation in a unit area to the number of plants present before operation in the same unit area. It is expressed in percentage.

$$
\mathrm{R}=\frac{\mathrm{q}}{\mathrm{p}} \times 100
$$

Where, $R$ is plant damaged (\%), $p$ is total number of plants per unit area before the weeding operation, $\mathrm{q}$ is the total number of plants damaged in the same unit area after the weeding operation.

\section{Field efficiency}

The ratio of effective field capacity to the theoretical field capacity, expressed as percentage.

$$
n_{w}=\frac{E F C}{T F C} \times 100
$$

$\eta_{e}=$ Field efficiency (\%), EFC = Effective field capacity, ha $h^{-1}, \mathrm{TFC}=$ Theoretical field capacity, ha $\mathrm{h}^{-1}$

\section{RESULTS AND DISCUSSION}

The machine was tested in the experimental plot of SVCAET \& RS, IGKV, Raipur for performance in upland paddy. The machine performance are expressed in terms of weeding efficiency, plant damaged, effective field capacity, field efficiency and fuel consumption. It was observed that the machine worked satisfactorily for weeding in 28 to $30 \%$ moisture content $(\mathrm{db})$ in the field. The field test results of developed power weeder are depicted in Table 2.

The machine shows the maximum weeding efficiency of $85.9 \%$ at 45 DAS than 20DAS (74.2\%). Whereas, plant damaged percentage was less, 3.75\% at 20 DAS than 45 DAS (8.26\%). The main reason for this may be, the height of the plant for 20 DAS was less as a result the machine had sufficient ground clearance for easily operation above crop in this stage. Similarly machine is operated in intra rows, as a result, the rice plants which is grow out of line were also damaged. The result clearly indicated that, the highest field efficiency was depicted at 45 DAS which is $9.37 \%$ more than 20 DAS. As the machine is working with petrol start kerosene run engine, there was no huge significant variation for fuel consumption at 20 and 45 DAS respectively.

Table 2: Test results of developed power weeder

\begin{tabular}{ccc}
\hline Particulars & \multicolumn{2}{c}{ Results } \\
\hline & 20 DAS & 45 DAS \\
\hline Weeding Efficiency, $\eta_{\mathrm{w}}(\%)$ & 74.20 & 85.90 \\
Plant damaged $(\%)$ & 3.75 & 8.26 \\
Effective field capacity, & 0.065 & 0.071 \\
$\quad\left(\right.$ ha $\left.\mathrm{h}^{-1}\right)$ & & \\
Field efficiency, $\eta_{\mathrm{e}}(\%)$ & 64.00 & 70.00 \\
Fuel consumption $\left(\mathrm{l} \mathrm{h}^{-1}\right)$ & 0.63 & 0.70 \\
\hline
\end{tabular}

\section{CONCLUSION}

The machine can be made up of easily available machine components such as engine, gearbox, sprockets and chain etc and can be fabricated and repaired by any workshop technician/skilled person or farmer for the satisfactory weeding in upland paddy for both at 20 and 45 DAS. The affordability of this machine promotes a convenient measure in mechanisation of weeding for the small and medium farmers in developing counties.

\section{ACKNOWLEDGEMENTS}

I express my sincere gratitude to the advisory committee, technical and non- technical staffs of SVCAET\&RS, Raipur for their support and guidance for conducting this research as a part of the M. Tech. thesis.

\section{REFERENCES}

Datta, S.K., Aragon, K.L. and Mlabugoe, J.A. 1974. Varietal difference in cultural practices for upland rice. Seminar Proceeding In. Rice Breeding and Varietal Environment. West Africa Rice Development Association. Manoroviabilaria, pp. 35-73.

Mahilang, K.K.S., Kumar, K. and Kanwar, G.R. 2013. Design and development of power operated rotary weeder for rice. B.Tech. Thesis, Indira Gandhi Krishi Vishwavidyalaya, Raipur, India. 
Khurmi, R.S. and Gupta, J.K. 2005. A Text Book of Machine Design.1025 pp. 14 edition. Eurasia Publishing House Pvt. Ltd., Ram Nagar, New Delhi.

Rangasamy, K., Balasubramanian, M. and K.R. Swaminathan. 1993. Evaluation of power weeder performance. Agricultural Mechanization in Asia, Africa and Latin America, 24(4): 16-18.

Sharma, H.C., Singh, H.B. and Fireson, G.H. 1977. Competition from weeds and their control in direct seeded rice. Weed Research, 17(2): 103-108.
Tajuddin, A. 2006. Design, development and testing of engine operated weeder. Agricultural Engineering Today, 30(5, 6): 25-29.

Varshney, A.C. Tiwari, P. S., Narang, S. and Mehta, C. R. 2004. Data Bookfor Agricultural Machinery Design. CIAE, Bhopal.

Victor, V.M. and Verma, A. 2003. Design and development of power-operated rotary weeder for wetland paddy. Agricultural Mechanization in Asia, Africa and Latin America, 34(4): 27-29. 
